\title{
The Psycho-Educational Practice of Mental Toughness in Dealing with Trauma
}

\author{
Anna M. S. van Niekerk ${ }^{1} \&$ Hester E. Roets ${ }^{2}$ \\ ${ }^{1}$ Educational Psychologist in Private Practice, Pretoria, South Africa \\ ${ }^{2}$ School of Psychology of Education, University of South Africa, Pretoria, South Africa \\ Correspondence: Anna M. S. van Niekerk, Educational Psychologist in Private Practice, Pretoria, South Africa. \\ Tel: 27-74-034-0081. E-mail: marisavniekerk@gmail.com
}

Received: October 7, 2017

Accepted: October 26, 2017

Online Published: November 20, 2017

doi:10.5539/ijps.v9n4p83

URL: http://doi.org/10.5539/ijps.v9n4p83

\begin{abstract}
This study investigated whether an intervention program, which was developed within the psycho-educational field, could support traumatized people to increase their mental toughness. This program is based on the four components of mental toughness, namely control, challenge, commitment and confidence. A valid and reliable psychometric instrument, the Mental Toughness Questionnaire 48 (MTQ48), has been successfully used in both the corporate and sports psychology world to determine people's mental toughness but has never before been tested in supporting traumatised people. Many corresponding aspects between mental toughness and trauma were discovered and used to compile a psycho-educational intervention program to support traumatized persons to develop increased mental toughness. An action research design was employed, where both qualitative as well as quantitative methods were used. Eight traumatized people participated in the research. The results of the study indicated that seven of the eight participants' overall mental toughness increased after the intervention program, and four of the eight participants' mental toughness components increased. All respondents indicated that they could better deal and cope with their trauma. The conclusion could be drawn that the psycho-educational intervention program, which was based on enhancing mental toughness, was successful in supporting the traumatised participants to increase their mental toughness.
\end{abstract}

Keywords: intervention program, mental toughness, MTQ48, trauma

\section{Introduction}

"The world breaks everyone and afterward, some grow strong at the broken places" (Roets \& Preston, 2008a).

As educational psychologists we are confronted, on a daily basis, with "broken people" and/or hurt people who have experienced trauma, such as divorce, abuse, suicide, death, housebreaking, bullying and natural disasters. Roets and Preston (2008b) stated that a single traumatic event can have lasting consequences on a person as well as on the people in their surroundings, including the environment and community in which they live. Professionally, we have experienced that some people have the ability to recover sooner than others who, albeit on the surface, seem to have been exposed to less traumatic conditions. The question existed whether it would be possible to support traumatised people to develop skills, knowledge and characteristics for them to "bend and adapt", like a tree in the wind, when they experience trauma, instead of "snap(ping) at the gust of the wind" when they are confronted with a traumatic experience (Roets \& Preston, 2008a). An initial review of literature concerning methods used to support traumatised people garnered the following results: Useful information exists regarding methods that a therapist can employ to support a client in developing characteristics and skills to approach trauma, but these sources are descriptive in nature and do not provide any programs for using specific strategies and techniques. Limited information exists about the expectations of the professional relationship between the therapist and the client during continuous psychotherapy, where the focus is on the effects of trauma on the client (Lamb, 1988; Corr, Nabe, \& Corr, 2006; James \& Gilliland, 2013).

Our search for methods that support traumatised people led to the exploration of the phenomenon called mental toughness. Mental toughness is defined as: "The quality which determines in large part how people deal effectively with challenge, stressors and pressure...irrespective of prevailing circumstances" (Clough \& Strycharczyk, 2012). UNISA (2002), Du Toit and Du Toit, M. (2002), Roos, Tedeschi and Calhoun (2004), 
Keeton (2009), and Preston (2013), defined trauma as stressful events, over which a person has no control. These stressful events cause high levels of anxiety that threaten or harm a person's emotional, physical and/or social well-being and interfere with the individual's normal daily functioning in such a way that a re-evaluation of the person's actions and thoughts are required. Strong emotional reactions have the potential to interfere with an individual's ability to function either at the scene or in the future (Mitchel, 1983). Literature was consulted to determine the phenomena of mental toughness and trauma respectively. The research question explored the following: "Would a psycho-educational program that aims to improve mental toughness in a traumatised person, lead to heightened mental toughness?"

\section{Exploring the Concepts of Mental Toughness and Trauma}

\subsection{Mental Toughness}

Mental toughness is a well-proven phenomenon in both sports psychology and in the corporate leadership world. The valid and reliable MTQ48 psychometric instrument was developed by Drs Peter Clough and Keith Earle and has been successfully used to determine people's mental toughness but has never been tested to ascertain its effectiveness when supporting traumatised people. Mental toughness has four vital components, namely control, challenge, commitment and confidence, commonly referred to as the 4C's model (Clough \& Strycharczyk, 2012; Mental toughness, 2012). Control has two sub-aspects, namely emotional control and control over a person's life. There is a very strong relation between mental toughness, stress management, performance and behaviour (Mental toughness, 2012; Clough \& Strycharczyk, 2012). The MTQ48 was established from three existing models, namely resilience, hardiness and psychological toughening. Mental toughness can be measured with a standardised questionnaire (Clough \& Strycharczyk, 2012; Horsburgh, Schermer, Veseleka, \& Vernon, 2008).

Bethany (2007) stated that a person's ability to gain insight into his or her stress responses and therefore be able to change his or her own reactions to his or her responses can provide the person with a feeling of control over the responses. It is at this point in trauma, where education about the "psychological basis for psychological phenomena", is addressed as psycho-education.

The developers and authors of the mental toughness measurement revealed that there is little evidence about the relationship between mental toughness and its applicable use in psychology. Mental toughness is not static and can be developed and enhanced as a skill in people. Clough and Strycharczyk (2012) stated that mental toughness intertwines both theoretical foundations, like confidence and resilience, and practical applications, for example visualisation and concentrating.

The first important aspect in developing a person's mental toughness is that a person should be willing to develop more mental toughness, implying that the individual would therefore be willing to take action (Scott, 1992; Sheikh, 2008; Clough \& Strycharczyk, 2012). Self-belief is an important buffer against adversity and crisis and a strong sense of self-belief is an important characteristic of mental toughness. For people to learn to believe in themselves, they should learn about who they are and start focusing on their positive characteristics and skills (Scott, 1992; Van den Aardweg \& Van den Aardweg, 1999; Strydom et al., 2002; Graham, 2004; De Villiers \& Van den Berg, 2012).

An inter-correlation exists between mental toughness, stress management, performance and well-being. Characteristics of mental toughness include inter alia the ability to effectively cope with stress and to recover from adversity and failures (Clough \& Strycharczyk, 2012). Therefore in supporting a client to increase his or her mental toughness, the client should be supported regarding how to better deal with stress and how to manage it. Positive self-talk is another aspect that supports a person who is dealing with stress, as it plays an important role in the development of a person's positive self-concept (Scott, 1992; Roos, Du Toit, \& Du Toit M, 2002; Clough \& Strycharczyk, 2012). A flexible person is better able to cope with negative emotions than a rigid person, as the individual will realise that he or she is still able to make choices and is not completely trapped inside his or her adversity. The therapist should support the client to demonstrate how the client can start to push his or her own boundaries, in spite of physical and emotional pain (Association for Qualitative Research (AQR), 2010a). Learned helplessness and the control component of mental toughness are closely intertwined. Learned helplessness implies a person's perception that things are out of his control—even things that he can control (Sue, D., Sue, D. W., \& Sue, S., 2010; Brooks \& Clarke, 2011; Clough \& Strycharczyk, 2012; Egan, 2014). If a person is able to unlearn the learned helplessness, that particular individual can become more mentally tough (Clough \& Strycharczyk, 2012).

Another core aspect to developing mental toughness is goal setting. James and Gilliland (2013) concentrated on the value of accomplishment for a traumatised person. Sue, D., Sue, D. W. and Sue, S. (2010) also focused on the importance of taking action, which implies making changes in order to attain certain goals. 
Support systems, for example, peers, parents and coaches play an important role in the development of mental toughness and the client should be supported to determine whether he or she has a support system and should learn how to put a support system in place. The client will then become more able to increase his mental toughness characteristics, like resilience and persistence (Baron, Byrne, \& Branscombe, 2006; Clough \& Strycharczyk, 2012).

The aspects we search for in a mentally tough person are the following: a willingness to develop more mental toughness, a strong sense of self-belief, a focus on their positive characteristics, the ability to deal with and manage stress well, the presence and ability to perform positive self-talk, flexibility, the unlearning of learned helplessness, proper goal setting and the willingness to take action.

\subsection{Trauma}

Trauma can cause feelings of helplessness, and it must be remembered that what may be traumatic for one person might not necessarily be traumatic for another person (Roos et al., 2002). To determine whether an event was traumatic or not, a therapist can assess the impact the traumatic event had on an individual. A person's reaction to trauma is influenced by aspects such as genetic predisposition, personal history, personality traits, self-esteem, strengths, weaknesses, state of mind, past life experiences, coping skills, the social support system, the intensity of the event, the perception of the event, conflict, stress management skills and flexibility (James \& Gilliland, 2013; Roos et al., 2002; Scott \& Stradling, 2006; Sue, D., Sue, D. W., \& Sue, S., 2003; UNISA, 2002).

By acknowledging trauma, an individual attempts to regain the control that was lost during the traumatic event; a traumatized person should make a deliberate and active cognitive decision (Miller \& Harvey, 2001; Berson \& Berson, 2002; Bethany, 2007; Preston 2011). An empowering tool in a traumatized person's life is the ability to view himself or herself as a survivor and not as a victim (Roets, 2009). To properly support a traumatized person through therapy, it is important that the therapist addresses the impact of negative previous life events on the individual's self-concept and ego strength (Roets, 2009; James \& Gilliland, 2013). Flexibility allows a traumatized person to start to make sense of his or her life again, as rigidity complicates life and makes it difficult for a traumatized person to attempt to adapt to the changes in his or her life. Both self-awareness and positive self-appraisal will support a person to better deal with his trauma. The therapist should support a traumatized person to discover his or her defense mechanisms. People use defense mechanisms (e.g., withdrawal and fixation) to protect themselves from unwanted emotional, behavioural and cognitive patterns (James \& Gilliland, 2013; Meyer, Moore, \& Viljoen, 2003; Roets, 2009; Sue et al., 2010).

Characteristics that help a traumatized person to better deal with trauma are resilience, hardiness and optimism. Resilience, hardiness and optimism are integral parts of mental toughness and therefore the hypothesis was made that mental toughness supports a traumatised person to better handle his or her trauma (Clough \& Strycharczyk, 2012).

Trauma and the accompanied stress can have negative physical and psychological implications on a person's health. To empower the traumatized person, he or she should learn about the normal symptoms, as well as the neurological processes that take place in his or her brain, due to the abnormal circumstances (Meichenbaum, 1995; Roos et al., 2002; Tedeschi \& Calhoun, 2004; Roets, 2009). Play therapy (e.g., clay work, storytelling, bibliotherapy) and cognitive therapy (e.g., relaxation training, thought stopping, cognitive restructuring) are powerful aids that support a traumatized person to learn how to emotionally deal with sensorial trauma stimuli (Meichenbaum, 1995; James \& Gilliland, 2013). A support system consisting of family and friends protects a stressed person from the destruction caused by stress (Kleber \& Brom, 1992; Preston, 2013; Roos et al., 2002).

There are many aids to support a traumatized person who attempts to better deal with his or her trauma. These aids include the following: facing the trauma, making a cognitive decision to take action, being flexible and not rigid to adapt to the changes in his or her life, applying self-awareness, performing positive self-appraisal and positive self-talk, discovering and recognizing his or her defense mechanisms, developing resilience, hardiness and optimism, learning how effectively to deal with his or her stress, having a good support system, realizing that his or her perceptions are not necessarily the truth, setting reachable goals and refraining from becoming a helpless person, and committing to better management of his or her trauma.

\section{Corresponding Aspects between the Literature of Mental Toughness and Trauma}

In our study that sought to determine how to support a traumatised person to develop more mental toughness to gain skills that would support the individual to better deal with trauma, we analysed the corresponding aspects of the literature that was reviewed regarding mental toughness and trauma. The corresponding aspects are the following: action taking, the importance of the "self", facing negativity and adversity, the importance of support 
systems, flexibility and adjustment, dealing with guilt and self-blame, the role of self-talk, people's perceptions, goal-setting, commitment, helplessness/learned helplessness and dealing with stress.

\section{Research Design}

Action research was used in this study as we aimed to narrow the gap between theory and practice (Holly, Arhar, \& Kasten, 2005; Norton, 2009; Somekh \& Lewin, 2011). In the cyclical process of action research, experience is gained and evaluations are made to determine whether experience and practice meet, at which point the spiral activity recommences (Norton, 2009; McNiff \& Whitehead, 2011; Mc Ateer, 2013).

Somekh and Lewin (2011) indicated that while action research often involves sources of qualitative data on the basis of analysis, it also often involves quantitative data. The empirical study was a mixed method research design that utilised both qualitative and quantitative methods in an action research format. Quantitative data deals with methods and techniques that acquire the most appropriate data to explore the research aims. Quantitative data that was used in this study was the MTQ48 Questionnaire. All eight participants of the study completed the MTQ48 Questionnaire prior to the commencement as well as after the psycho-educational intervention program.

Alternately, qualitative data has its roots in people's verbal expressions, metaphors and other symbols as the researcher attempts to gain knowledge and understand the participant's life-world and determine how the participant experiences phenomena (Norton, 2009; Welman, Kruger, \& Mitchell, 2010). Qualitative research in this study included interviews (both structured and unstructured), which were conducted with participants prior to, during and after the psycho-educational program. Further qualitative media that were used included metaphors and play therapy (e.g., bibliotherapy, sand play, clay work and storytelling).

\subsection{Sample}

We made use of a non-probability sample in this study. This implies that not all the persons in the greater population had the opportunity to be included in the research (Trochim, 2006; Welman et al., 2010). We invited traumatised persons in our immediate environment to participate in the study. This decision was taken under consideration of practical implications, such as securing a meeting venue, as well as traffic, transport and time constraints that often impact face-to-face interactions (Welman et al., 2010; Statistics Canada, 2013). Eight South African females in the age group of 31 years and 62 years were included in the study, and of these participants, some were English speaking and others were Afrikaans speaking.

Before a person was considered for participation in the study, the individual's mental toughness was determined, since the prerequisites for the study included both low/average mental toughness and having experienced trauma. An individual interview was conducted with each client. This semi-structured interview focused on determining whether and to what extent the client considered her mental toughness to be low. During the interview the client completed the standardized MTQ 48 Questionnaire to confirm her low/average mental toughness. Once the level of mental toughness was determined, the person was then invited to become part of the study. The trauma that the participants experienced included the following: Participant A: emotional abuse; Participant B: divorced twice, physical and emotional abuse by second husband, divorce of parents; Participant C: death of husband; Participant D: post-natal depression; Participant E: living with bipolar disorder; Participant F: death of dad; Participant G: death of son; Participant H: death of husband.

The consequences of a non-randomised sample are that the researcher cannot control all nuisance variables, which could lead to low generalisation and causal explanations (Mouton, 2001; Welman et al., 2010; Statistics Canada, 2013). A pre-test confirmed that the participants were at least similar in terms of the dependant variable, which was their mental toughness level. We made use of an organisation development report (pre-test) to identify trends and patterns of similarity in the group. A post-test was performed after the completion of the psycho-educational program, and differences in respect of the dependant variable (mental toughness) were used to deduce whether it was the result of the psycho-educational program as the independent variable (Welman, 2010).

\subsection{Data Collection}

To focus on the corresponding results of different research methods to establish new insights in this study the data collection methods were characterised by triangulation (Somekh \& Lewin, 2011).

\subsection{Quantitative Instruments}

The MTQ48 Questionnaire was the quantitative instrument that was used in this study. It was utilised for both pre-data collection and post-data collection. The MTQ48 consists of 48 items which are in the format of a 
questionnaire and it takes approximately 10 minutes to complete the questionnaire online. Responses are captured by a five-point Likert scale that measures a person's mental toughness across four scales, which are control, challenge; commitment and confidence. The overall consistency of the MTQ48 is 0.9 or above. It means that the reliability score of the MTQ48 is a high or acceptable score. The validity score for the MTQ48 ranges from 0.25 to 0.42 which indicates a high or acceptable score. The MTQ48 is thus a valid and reliable measuring instrument (Collins et al., 2000; Association for Qualitative Research (AQR), 2010a; Crust \& Swann, 2011; Clough \& Strycharczyk, 2012). The MTQ48 uses sten scales to report scores as stens, which is a standardised psychometric method of scoring. The MTQ48 post-test was utilised at the conclusion of the psycho-educational program to determine whether the participants' mental toughness increased or remained the same. This report is called a distance travelled report. To identify patterns and trends in the voluntary traumatised group of the study, we made use of an organisation development report, which was in the form of a histogram, as like most psychometric data the MTQ48 was analysed by a sten scale (Association for Qualitative Research (AQR), 2010b).

\subsection{Qualitative Instruments}

Qualitative research in this study was used to observe the traumatized person's life world and the change in his behaviour and actions during the participation in the psycho-educational program. Qualitative research in this study included interviews that were both structured and unstructured in nature, which were conducted with participants prior to, during and after the psycho-educational program. Other qualitative media that were used included metaphors, bibliotherapy and play therapy (e.g., claytherapy and sandplay). Semi-structured questionnaires that were completed prior to and after commencement of the therapy (as part of the cyclic process of action research), were also used.

\subsection{Researchers' Observations}

Observation occurred throughout the eight-session therapy process, as we wanted to garner insight into both the traumatized individuals' life worlds that included their behaviour and activities, as well as information pertaining to the cyclic process of improving their mental toughness to better cope with their trauma (Norton, 2009; Somekh \& Lewin, 2011). We summarised each session using process notes.

\subsection{Individual Therapy}

We acted out roles of being facilitators during the therapy sessions. This implied that we had to make conscious efforts to stand back and let each individual develop at her own pace. According to the Department of Educational Studies (UNISA, 2002) this role helped the participants to observe and reflect on their individual skills. Each session of the study was followed-up by reflection and observation of the information, skills, knowledge and change that the traumatized persons gained and/or lost through the therapy so that we could compile an effective and relevant program that will be applicable for use by therapists and psychologists in the future (Hornby, 1990).

\section{Results}

\subsection{Data Analysis}

The MTQ48 Questionnaire was scored according to the psychometric test specifications and was interpreted quantitatively. The qualitative data was analysed in a systematic manner within the qualitative paradigm (De Vos, 2006).

\subsection{Discussion of Research Findings}

As evident from Figure 1, four participants' Overall Mental Toughness scores increased with 4 stens each, two participants' scores increased with 2 stens for each participant, one participant moved up 1 sten score and one participant's Overall Mental Toughness did not increase with a full sten score, though her scores exhibited increases in challenge where her sten of 2 increased to a sten of 4, her life control's sten of 3 increased to a sten of 4 , her emotional control moved up from a sten of 4 to a sten of 6 and her confidence in abilities improved from a sten of 5 to a sten of 6 . 


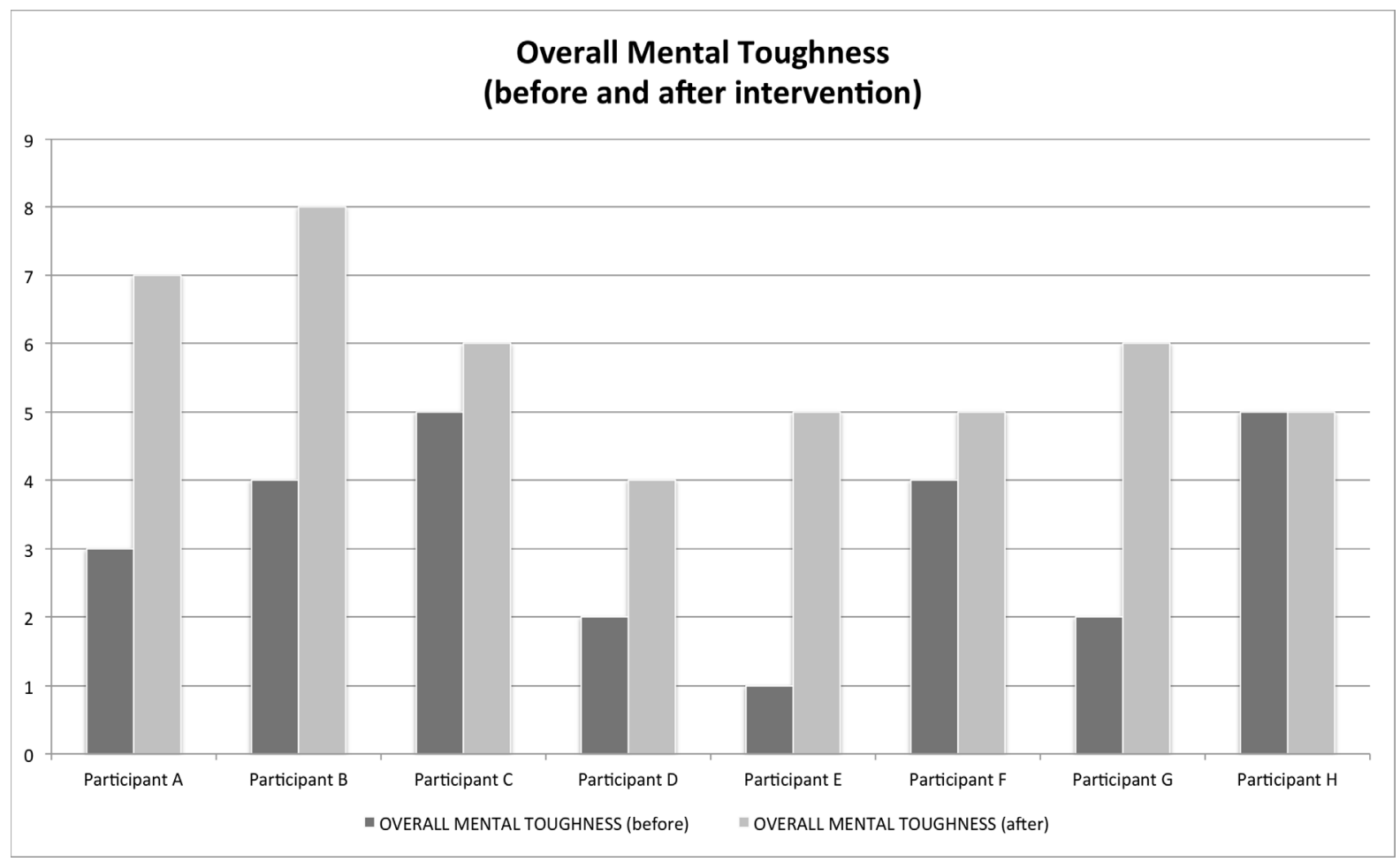

Figure 1. Overall mental toughness (before and after intervention)

The results of Figure 2 indicate that for all the participants from the study, the mental toughness components that increased most after the intervention were confidence and confidence in abilities, which increased with an average score of 3 and 3.25 respectively. Five participants (A, D, E, F, G) had below average scores for confidence before the therapy commenced, and three participants $(\mathrm{B}, \mathrm{C}, \mathrm{H})$ had average scores for confidence in the pre-tests. It was obvious through the intervention sessions (through the qualitative observation and feedback from participants) that all participants struggled to have confidence in themselves and their abilities and self-doubt was particularly prevalent. In the post-test, six of the participants (A, C, D, F, G, H) gained average scores for confidence and two participants (B and E) had above average scores for confidence. In the pre-test for confidence in abilities six of the eight participants (A, B, D, E, F, G) scored below average and two participants $(\mathrm{C}$ and $\mathrm{H})$ obtained average scores. In the post-test of confidence in abilities, three participants (B, E, G) scored above average, three participants $(\mathrm{A}, \mathrm{C}, \mathrm{H})$ gained average scores and two participants $(\mathrm{D}, \mathrm{F})$ scored below average. 


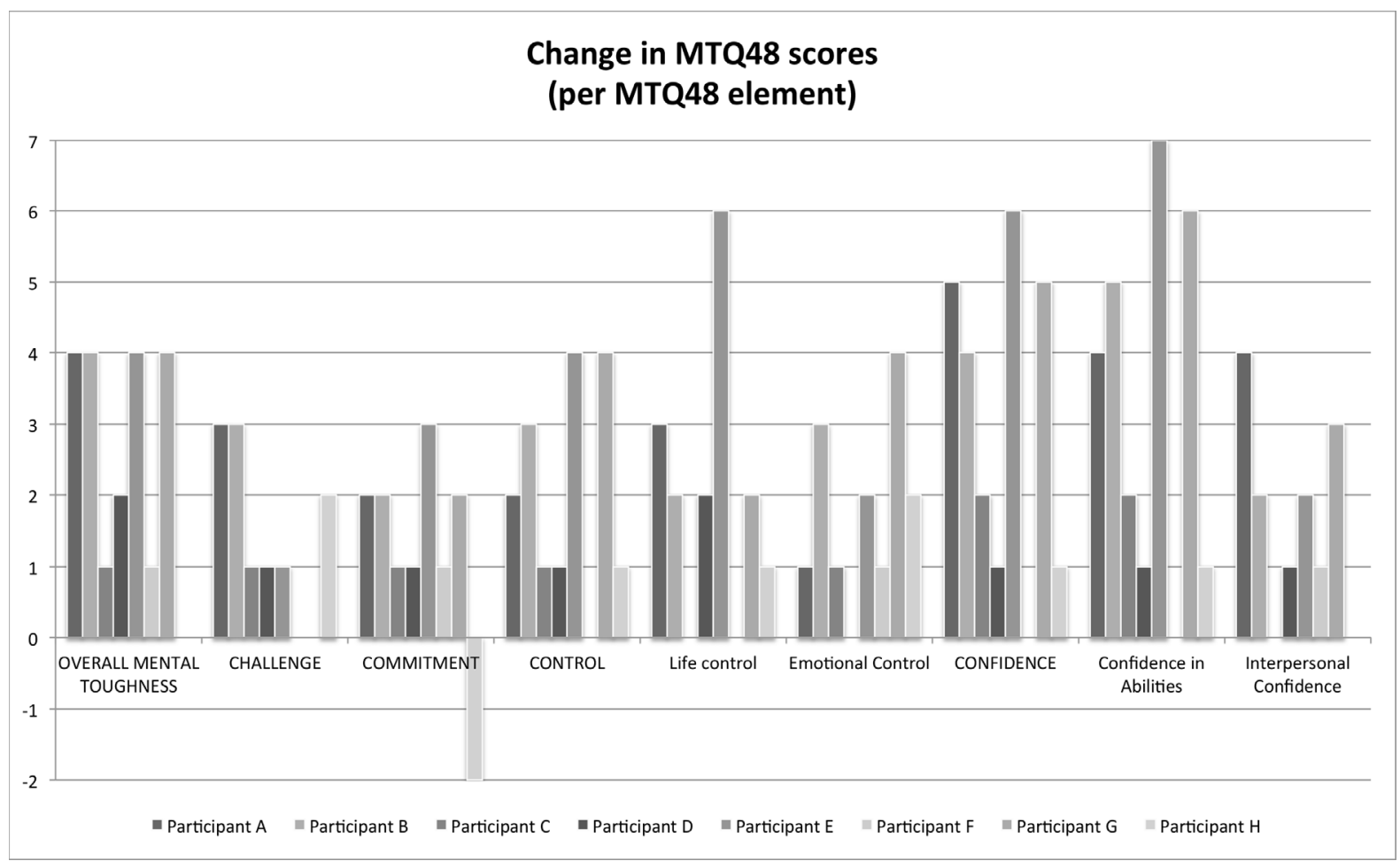

Figure 2. Change in MTQ48 scores (per MTQ48 element)

Figure 3 displays an organisation development report of the eight participants of the study to ascertain the results for each scale of the MTQ48 Questionnaire before and after the intervention therapy sessions. The difference between the means of the pre- and post-tests indicates the average point with which a score increased. From Figure 3 it is evident that all components of mental toughness increased during the intervention sessions. The average score of the Overall Mental Toughness of the eight participants together increased with a score of 2.5. Challenge increased with an average score of 1.375, commitment increased with 1.25, control increased with 2, life control increased with 2, emotional control increased with 1.75 , confidence increased with 3 , confidence in abilities increased with 3.25 and interpersonal confidence increased with 1.625. 


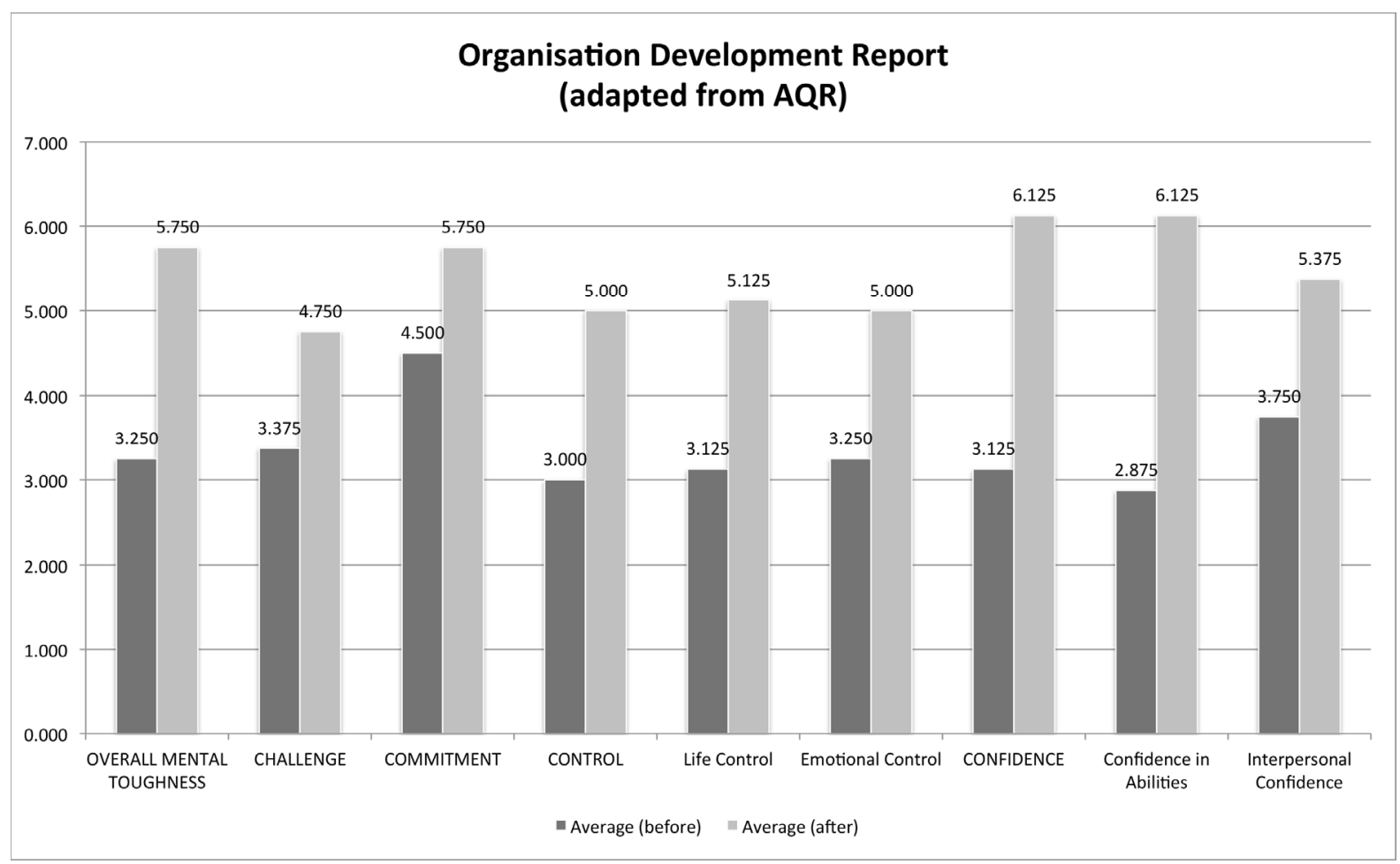

Figure 3. Organisation development report (adapted from AQR)

The mean of the lowest score in the pre-test, of the eight participants, was confidence in abilities, with a score of 2.875 and the mean of the highest score in the pre-test was commitment with a score of 4.5. The mean with the lowest score in the pre-test, of all eight participants, was challenge with a score of 4.75 and the mean of the highest score in the pre-test was confidence in abilities with a score of 6.125.

An important further question arose, concerning whether the participants found that they can better deal with their various traumas. This was determined through observation as well as through the therapy sessions and feedback of the participants. What follows is a summary of the participants' comments after the intervention sessions.

Participant A: "I'm more confident in my abilities. It's still difficult to live with my husband, but therefore I force myself to reach out more to others".

Participant B: "I have learned why I emotionally tend to overact easily. I'm less anxious and I experience a huge sense of relief."

Participant C: "I feel I can go on with my life again and I feel better about myself. I have practical aids and I know what to do when I get overwhelmed."

Participant D: "I feel more in control of my world which felt totally out of control. I understand why and how my body reacted on my trauma. I now have a weekend support system in place."

Participant E: It was freeing to realise that I'm a survivor and not a victim of my bipolar disorder. My life changed from just existing to living again."

Participant F: "I can face my emotions for the first time in my life. I try to see myself not only as a sister and a good friend to men, but also in the role of a woman."

Participant G: "I went from suicidal thoughts back to life. I've realised that I have another son who is still alive and that I can't take life away from him."

Participant H: "I don't feel guilty anymore for putting my husband in a care centre. I try to appreciate my positive characteristics more." 


\section{Discussion}

As mentioned previously evaluation is an important part of the cyclic process of action research. Some of the positive experiences of the participants were the importance that the therapist created an atmosphere where participants felt safe enough to open up and share their deepest emotions. The participants experienced empowerment in being able to gain insight into how and why they acted and reacted. The participants realized the importance of having a good support system and this comforted them, as they sometimes felt lonely in their traumas. The participants felt relief when they realized that they are "normal" in an "abnormal" traumatic situation. They also found empowerment in learning how to love and appreciate themselves more.

Some of the negative experiences of the therapy sessions which became positive experiences were that the participants discovered their defense mechanisms (which later on helped them to understand the ways in which they adapted to cope with the challenges in their lives). The participants acknowledged and confronted hurting emotions which they thought they had previously resolved, this experience was enlightening to some participants.

Although the psycho-educational intervention program is seen as being successful in supporting traumatized people, the study had the following limitations:

It was a once-off study that was conducted over a short period of eight weeks, therefore no conclusions can be made about the long-term effects of the intervention program. A non-probability sample was used in the study and therefore not all the people in the greater population had the opportunity to be included in the research. The results are thus only valid for the population of this study. All participants came from an economically affluent area, therefore the results cannot be generalised to disadvantaged areas. In this study only English and Afrikaans speaking people were represented. A larger sample that includes other racial groups of South Africa is required to represent the population of South Africa. All the participants were women, therefore the results cannot be generalised to men. All the participants were white. South Africa is known as the rainbow nation and a larger sample of the nation is required to accurately represent the different cultural groups.

James and Gilliland (2013) stated that culture interacts with trauma (although the way in which it does is still controversial). In this regard, the study of a white South African female group was useful. Traumatised people are unique individuals in different stages of their traumas and they have to deal with different emotions. An intervention program that addresses all the participants' issues at the same time therefore is not practically feasible. In the future, such a study could be limited to people who experienced the same kind of trauma, for example the death of a child.

The implications for practice can be seen in the contributions that were made by this study: According to our literature research as well as communication with Dr Peter Clough, who is one of the editors of the book "Developing mental toughness" (2012) and is a developer of the MTQ48 Questionnaire, this study is the first to research the phenomenon of mental toughness in the trauma field. Therefore the study contributes to the pool of knowledge of psychology and trauma (both theoretically and practically). The literature review and intervention program provides a sound basis for determining the mental toughness of traumatized people. A psycho-educational intervention therapy program has been compiled for practical use to support traumatized persons. Due to space constraints this program will be discussed in a future article.

The findings in the pre- and post-tests indicated that the mental toughness components that increased most after the intervention were confidence and confidence in abilities. It was obvious through the intervention sessions (through the qualitative observation and feedback from participants) that all participants struggled with having confidence in themselves and their abilities and that they did not believe enough in themselves. This finding might suggest that therapists need to concentrate their psychological support to traumatized persons regarding these two components of mental toughness. The study provides hope, as a glimpse into the lives of traumatised persons indicated that although it is a painful and tough journey, the "light of hope" will shine through in their lives again.

\section{Conclusion}

From the above-mentioned discussion the conclusion could be drawn that the psycho-educational program was successful in supporting the traumatized participants to increase their mental toughness. In this process the participants also learned to better deal and cope with their traumas.

\section{References}

Association for Qualitative Research (AQR). (2010a). Mental toughness Questionnaire: A user guide. United Kingdom: AQR Ltd. 
Association for Qualitative Research (AQR). (2010b). Organisation development report: Sample report. United Kingdom: AQR Ltd.

Baron, R. A., Byrne, D., \& Branscombe, N. R. (2006). Social Psychology (11th ed.). United States of America: Pearson Education, Inc.

Berson, M. J., \& Berson, I. R. (2002). Children's responses to trauma. Kappa Delta Pi Record, 38(2), 73-76. https://doi.org/10.1080/00228958.2002.10516346

Bethany, J. (2007). Psychoeducation for survivors of trauma. Perspectives in Psychiatric Care, 43(3), 123-131. https://doi.org/10.1111/j.1744-6163.2007.00121.x

Brooks, A., \& Clarke, L. (2011). Combining client-centered therapy with attribution theory. Mental Health Practice, 14(9), 34-37. https://doi.org/10.7748/mhp2011.06.14.9.34.c8527

Clarke, W. (2008). Working with survivors of trauma. Mental Health Practice, 11(7), 14-17. https://doi.org/10.7748/mhp2008.04.11.7.14.c6481

Clough, P., \& Strycharczyk, D. (2012). Developing mental toughness: Improving performance, wellbeing and positive behaviour in others. United States: Kogan Page Limited.

Collins, K. J., Du Plooy, G. M., Grobbelaar, M. M., Puttergill, C. G., Terre Blanche, M. J., Van Eeden, R., ... Wigston, D. J. (2000). Navorsing in die sosiale wetenskappe: Fakulteit Lettere en Wysbegeerte. In Enigste studiegids vir RSC201-H. Pretoria: UNISA.

Corr, C. A., Nabe, C. M., \& Corr, D. M. (2006). Death and dying, life and living (5th ed.). United States of America: Thomson Wadsworth.

Crust, L., \& Swann, C. (2011). Comparing two measures of mental toughness. Personality and Individual Differences, 50(2), 217-221. https://doi.org/10.1016/j.paid.2010.09.032

De Villiers, M., \& Van den Berg, H. (2012). The implementation and evaluation of a resiliency programme for children. South African Journal of Psychology, 42(1), 93-102. https://doi.org/10.1177/008124631204200110

De Vos, A. S., Schulze, S., \& Patel, L. (2006). The science and the professions. In A. S. De Vos, H. Strydom, \& C. B. Fouche, CSLDelport (Eds.), Research at grass roots for the social sciences and human service professions (pp. 3-26). Pretoria: Van Schaik.

Egan, G. (2014). The skilled helper: A problem-management and opportunity-development approach to helping (10th ed.). United States of America: Brooks/Cole Cengage Learning.

Graham, A. (2004). Life is like the seasons. Childhood Education, 80(6), 317-321. https://doi.org/10.1080/00094056.2004.10521278

Holly, M. L., Arhar, J., \& Kasten, W. (2005). Action research for teachers: Travelling the yellow brick road (2nd ed.). Upper Saddle River, New Jersey: Pearson, Merill Prentice Hall.

Hornby, G. (1990). A humanistic developmental model of counselling: A psycho-educational approach. Counselling Psychology Quarterly, 3(2), 191-203. https://doi.org/10.1080/09515079008254247

Horsburgh, V. A., Schermer, J. A., Veselka, L., \& Vernon, P. A. (2008). A behavioural genetic study of mental toughness and personality. Personality and Individual Differences, 46, 100-105. https://doi.org/10.1016/j.paid.2008.09.009

James, R. K., \& Gilliland, B. E. (2013). Crisis intervention strategies (7th ed.). United States of America, Belmont: Brooks/Cole Cengage Learning.

Keeton, M. (2009, March 03). How trauma affects the brain. Retrieved from http://karunacounseling.wordpress.com/2009/03/03/how-trauma-affects-the-brain/

Kleber, R. J., \& Brom, D. (1992). Coping with trauma. Amsterdam/Lisse: Swets \& Zeitlinger.

Lamb, D. H. (1988). Loss and grief: Psychotherapy strategies and interventions. Psychotherapy, 25(4), 561-569. https://doi.org/10.1037/h0085382

McAteer, M. (2013). Action research in education. London: Sage. https://doi.org/10.4135/9781473913967

McNiff, J., \& Whitehead, J. (2011). All you need to know about action research (2nd ed.). London: Sage.

Meichenbaum, D. (1995). A Clinical Handbook/Practical Therapist Manual for assessing and treating adults with Post-Traumatic Stress Disorder. Canada: Institute Press. 
Mental, T. (2012). Mental Toughness MTQ48. Retrieved from http://www.mentaltoughness.co.nz/

Meyer, W. F., Moore, E., \& Viljoen, H. G. (2003). Personology: From individual to ecosystem (3rd ed.). Sandown: Heinemann Publishers (Pty) Ltd.

Miller, E. D., \& Harvey, J. H. (2001). The interface of positive psychology with a psychology of loss: A brave new world? American Journal of Psychotherapy, 55(3), 313-322.

Norton, L. S. (2009). Action research in teaching and learning: A practical guide to conducting pedagogical research in universities. London and New York: Routledge Taylor \& Francis Group.

Preston, L. D. (2011). Supervisor notes for Intern Educational Psychologist student. Pretoria: Unitas Hospital.

Preston, L. D. (2013). Conquering trauma: From victim to survivor. Pretoria: UNISA.

Roets, H. E. (2009). Class notes for MEd-Guidance students. Pretoria: University of South Africa.

Roets, H. E., \& Preston, L. D. (2008a). Using the phenomena of human resilience in the impact phase of trauma intervention. Pretoria: University of South Africa.

Roets, H. E., \& Preston, L. D. (2008b). Using ego strengths for initial diagnostic criteria: A Psycho-educational Perspective. Pretoria: University of South Africa.

Roos, V., Du Toit, R., \& Du Toit, M. (2002). A counsellor's guide in dealing with trauma, death and bereavement. Pretoria: University of Pretoria.

Scott, D. (1992). Stress that motivates: Self-talk secrets of success. United States of America: Bawden Printing Company.

Scott, M., \& Stradling, S. G. (2006). Counselling for Post-Traumatic Stress Disorder (3rd ed.). London: Sage.

Sheikh, A. I. (2008). Theory and practice posttraumatic growth in trauma survivors: Implications for practice. Counselling Psychology Quarterly, 21(1), 85-97. https://doi.org/10.1080/09515070801896186

Somekh, B., \& Lewin, C. (2011). Theory and methods in social research (2nd ed.). London: Sage.

Steel, P. (2007). The nature of procrastination: A meta-analytic and theoretical review of quintessential self-regulatory failure. Psychological Bulletin, 133(1), 65-94. https://doi.org/10.1037/0033-2909.133.1.65

Strydom, I., Roets, E., Wiechers, E., \& Krüger, D. (2002). Inleidende oriëntering: Voorligting in opvoedkundige kontekste met spesialisering in skoolvoorligting (Hons BEd). Enigste studiegids vir OSV 451-3/OSV 411-R. Pretoria: Universiteit van Suid-Afrika.

Sue, D., Sue, D. W., \& Sue, S. (2003). Understanding abnormal behaviour (7th ed.). New York, Boston: Houghton Mifflin Company.

Sue, D., Sue, D. W., \& Sue, S. (2010). Understanding abnormal behaviour (9th ed.). New York, Boston: Houghton Mifflin Company.

Tedeschi, R. G., \& Calhoun, L. G. (2004). Posttraumatic Growth: Conceptual foundations and empirical evidence. Psychological Inquiry, 15(1), 1-18. https://doi.org/10.1207/s15327965pli1501_01

Trochim, W. M. K. (2006). Non-probability sampling. Research Methods Knowledge Base. Retrieved from http://www.socialresearchmethods.net/kb/sampnon.php

UNISA. (2002). Short course in crisis debriefing and trauma counselling. Pretoria: Centre for Community Training and Development, University of South-Africa.

Van den Aardweg, E. M., \& Van den Aardweg, E. D. (1999). Psychology of education: A dictionary for students (2nd ed.). Pretoria: E \& E Enterprises.

Welman, C., Kruger, F., \& Mitchell, B. (2010). Research methodology (3rd ed.). Cape Town: Oxford Press.

\section{Copyrights}

Copyright for this article is retained by the author(s), with first publication rights granted to the journal.

This is an open-access article distributed under the terms and conditions of the Creative Commons Attribution license (http://creativecommons.org/licenses/by/4.0/). 